\section{Comparison between fractional Co2 laser-triamcinolone injec- tion combination therapy and triamcinolone injection monotherapy for keloid}

\author{
M. Yulianto Listiawan, ${ }^{1}$ \\ Dwi Murtiastutik, ${ }^{1}$ Willy Sandhika, ${ }^{2}$ \\ Brama Rachmantyo, ${ }^{1}$ \\ Putri Hendria Wardhani ${ }^{1}$
}

${ }^{1}$ Department of Dermatology and

Venereology; 'Department of Anatomic

Pathology, Faculty of Medicine,

Airlangga University, Dr. Soetomo

General Hospital, Surabaya, Indonesia

\begin{abstract}
The histopathologic view of keloid shows dense fibroblasts and bundles of collagen throughout dermis. Treatment that completely cure keloid still not exist, although there are many treatment options. The monotherapy fractional $\mathrm{CO}_{2}$ laser shows good results, but is still as an adjuvant therapy. Fractional $\mathrm{CO}_{2}$ laser affects fibroblast and its functions in producing collagen. The combination therapy will combine the selective phototermolysis effect of $\mathrm{CO}_{2}$ lasers with antimitotic and antiinflammatory effects of corticosteroids. This study was an open trial with parallel design that compared fractional $\mathrm{CO}_{2}$ laserintralesional triamcinolone acetonide combination therapy (treatment group) and intralesional triamcinolone acetonide (control group) in keloid patients with collagen density as evaluation parameter. The dose of triamcinolone was $10 \mathrm{mg} / \mathrm{ml}$ of $0.05-0.1$ $\mathrm{ml} / \mathrm{cm}^{2}$ of keloid. Fractional $\mathrm{CO}_{2}$ laser energy setting was $10-20 \mathrm{~mJ}$. The decrease of collagen density in control and treatment group was significant $(\mathrm{p}=0.008$ and $\mathrm{p}=0.001$ ), although the decrease difference between control and treatment group was not significant $(\mathrm{p}=0.328)$. The collagen density that decrease in a shorter time shows that fractional $\mathrm{CO}_{2}$ laser could be a good combination therapy.
\end{abstract}

\section{Introduction}

Keloid is benign hyperplasia of the fibrous tissue of the skin. Keloid is scar tissue that grows beyond the border of the initial injury. Symptoms that can occur are pain and itching. The histopathologic view shows dense fibroblasts and bundles of col- lagen appearing throughout the thickness of the dermis. Fibroblast apoptotic rate in the keloid is lower than in the normal skin. ${ }^{1,2}$ The excessive collagen is due to an imbalance between the formation and degradation of extracellular matrix. ${ }^{3-5}$ Keloidmore affects African, Asian and Latin American ethnicities. Vulnerability genetically increases the risk of keloid $15 \%$ greater than in the population. ${ }^{4}$ Prevalence of keloid patients treated in Dermatovenereology Departement Dr. Soetomo Hospital Surabaya is $1.4 \%$ (83 patients) by $2013,1.6 \%$ (80 patients) by 2014 , and $1.5 \%$ (74 patients) by 2015 . The number of patients is a combination of the number of new and old patients. Keloid can result in a physical and psychological problem. Physical problems may be itchy, rigid skin, scar contractures, and pain symptoms. Psychological problems include confidence disorders, impaired daily activities, anxiety, and depression. ${ }^{3,6}$ There is no single treatment modality that is considered superior for the treatment of keloids. Treatment that cure the keloid completely still do not exist, although there are many treatment options available. ${ }^{4,6}$

First-line keloid therapy is intralesional corticosteroid injection, but give more results in small and early-stage keloid. ${ }^{7}$ Second-line therapy, surgical excision, needs to be considered if the keloid does not improve after first-line therapy for 12 months. Surgical therapy is not recommended as a single therapy because the high rate of keloid recurrence $(50-100 \%)$, can even form a larger keloid of early keloids. Second-line therapy that can be used in addition to surgical excision is laser. ${ }^{1,3}$

Intralesional triamcinolone acetonide injection therapy showed 50\% $-100 \%$ efficacy. The recurrence rate of this therapy reaches $33 \%$ in 1 year and $50 \%$ in 5 years. ${ }^{6}$ The Carbondioxide $\left(\mathrm{CO}_{2}\right)$ laser is an ablative laser, a continuous ablation effectively treating the keloid, but a long wound healing time of 4-8 weeks. The recurrence rate reached $92.3 \%$. Continuous $\mathrm{CO}_{2}$ laser followed by intralesional triamcinolone acetonide injection has better effectiveness than $\mathrm{CO}_{2}$ laser therapy or triamcinolone acetonide monotherapy. The rate of keloid recurrence that received combination therapy is reduced to $15.4 \%{ }^{7}$ Fractional $\mathrm{CO}_{2}$ lasers begin to be used for keloid because it has a shorter healing period. The monotherapy fractional $\mathrm{CO}_{2}$ laser shows good results, without recurrence after one year. The study was a case series with 8 patients with hypertrophic scars and keloids. Fractional $\mathrm{CO}_{2}$ lasers are still an adjuvant therapy because no studies have demonstrated the superiority of $\mathrm{CO}_{2}$ lasers over intralesional triamci-
Correspondence: Putri Hendria Wardhani, Department of Dermatology and Venereology, Faculty of Medicine, Airlangga University, Dr. Soetomo General Hospital, Surabaya, Indonesia

Tel: +62315501609

E-mail: putri_h_w@yahoo.com

Key words: $\mathrm{CO}_{2}$, keloid, laser, therapy, triamcinolone

Contributions: All the authors contributed equally.

Conflict of interest: The authors declare no potential conflict of interest.

Received for publication: 1 February 2119 Accepted for publication: 11 February 2119

This work is licensed under a Creative Commons Attribution-NonCommercial 4.0 International License (CC BY-NC 4.0).

(C) Copyright M.Y. Listiawan et al., 2019 Licensee PAGEPress, Italy

Dermatology Reports 2019; 11(s1):8032 doi:10.4081/dr.2019.8032

nolone acetonide injection. ${ }^{8}$

The combination therapy of fractional $\mathrm{CO}_{2}$ laser with intralesional triamcinolone acetonid injection for the treatment of keloid has never been studied in Dr. Soetomo Hospital Surabaya. Fractional $\mathrm{CO}_{2}$ laser is an ablative laser emitted in the form of laser light columns forming a microscopic treatment zone (MTZ). The MTZ is partially ablated area and the other part is still intact, allowing for a faster healing time compared to continuous $\mathrm{CO}_{2}$ lasers. ${ }^{7,9}$ Fractional $\mathrm{CO}_{2}$ laser affects fibroblast and its functions in producing collagen. ${ }^{10}$ The combination therapy will combine the selective phototermolysis effect of $\mathrm{CO}_{2}$ lasers with the antimitotic and antiinflammatory effects of corticosteroids. Keloid to be studied excluding keloid in the face area. This research is expected to know the effectivity of combination therapy of $\mathrm{CO}_{2}$ fractional and injection of triamcinolone acetonid to keloid patient with collagen density parameter.

\section{Materials and Methods}

This study was an open trial with parallel design methods that compared combination therapy fractional $\mathrm{CO}_{2}$ laser with intralesional triamcinolone acetonide (treatment group) and monotherapyintralesional triamcinolone acetonide (control group) in patients with keloids. The sample of the 
study were all keloid patients who met the inclusion criteria, who underwent treatment at Skin Surgery Division Dermatoveneorology Clinic of Dr. Soetomo Hospital Surabaya. The number of samples in the treatment group were 13 patients and in the control group were 13 patients.Data collection performed by filling the data collection sheet. Data were analyzed by using MANOVA (Multivariate Analysis of Variance) test.

The Inclusion criteria are keloid patients, including new and old keloid, age 15 - 64 years. Patients have not been treated with triamcinolone acetonide injections, if they have undergone such therapy it should be longer than 4 weeks after the last therapy. Patients with keloids who relapse after previous keloid therapy. The general condition of the patient is good. Willing to follow the research and sign the informed consent.

The exclusion criteria are patients with keloids on the face. Keloid size is more than $1 \%$ of skin surface area. Patients with systemic disease requiring immunosuppression therapy. (e.g. systemic lupus erythemathosus and pemphigus). Patients with skin infections, diabetes mellitus, pregnancy, and breastfeeding. Patients who had been on $\mathrm{CO}_{2}$ laser therapy for keloid in the last 6 months.

Biopsy was taken from the lesion area by using punch biopsy $-4 \mathrm{~mm}$, before the biopsy was performed local anesthesia first, then the punch instrument was rotated while pressed to a sufficient depth. The tissue is lifted and released from the underlying skin tissue. Bleeding on the open wound was stopped. Biopsy performed 2 times, before and after therapy. The location of the initial biopsy in the middle of a keloid lesion. Final biopsy is taken in the same lesion, but in different locations. Collagen density is a proportion of collagen fiber in a one visual field of Masson's trichromestaining keloid slide with 400 times magnification.

Intralesional triamcinolone acetonide are performed according to the standard, using a $1 \mathrm{cc}$ syringe and 25-gauge needle. The dose used is $10 \mathrm{mg} / \mathrm{ml}$ of $0.05-0.1$ $\mathrm{ml} / \mathrm{cm}^{2}$ of keloid. Direct injection is done to the keloid mass with the needle pointing downward. Pressure to injection sites after injection is necessary to prevent drug fluids escaping from the lesions. Administration in 1 therapy did not exceed $30 \mathrm{mg}$. Therapy was done 2 times with a 3 -week break.

Fractional $\mathrm{CO}_{2}$ laser therapy is a $\mathrm{CO}_{2}$ ablation laser therapy in fractionalmode with 10-20 mJ energy. Less energy for older and soft lesions, larger for new and hard lesions. $2.5 \%$ lidocaine anesthetic cream and $2.5 \%$ prilocaine were applied and 1 hour occlusive before laser therapy, then removed shortly before laser was done. The patient's eyes are covered with eye protector, doctors wear handschoen, masks, and protective goggles. Keloid is disinfected with $70 \%$ alcohol. The hand piece is directed perpendicular to the lesion, then the foot pedal is stepped on to fire the laser. The lesions were cooled with a cool, sterile $0.9 \% \mathrm{NaCl}$ gauze. Treatment was performed in the treatment group 1 times before intralesional triamcinolone injection.

\section{Results}

This study involved more female patients than male patients, but the sex of the patients between the control group and the treatment was homogeneous $(p=0.694)$. The largest number of patients by age is in the 15-24 age group. Results of age data processing of keloid patients obtained the youngest age is 18 years old and the oldest is 58 years. The age group of patients between the controls did not differ from treatment group with $\mathrm{p}=0.537$.

The shortest length of illnesskeloid in the study subjects was for 6 months and included in the group of 0.5-1 years of illness. Most research subjects suffer from keloid more than 4 years. The longest illness is 15 years. The homogeneity test showed that the length of keloid pain between the control group and the treatment group was not homogeneous. A total of 17 patients $(65.4 \%)$ had already been on treatment for keloids, but only 9 of 26 patients $(34.6 \%)$ were on standard treatment of triamcinolone acetonide injections.

The collagen density in the control and treatment group decreased significantly ( $p=0.008 \& p=0.001$, respectively), The average collagen density in the control group decreased from $85.15 \pm 4.40 \% /$ visual fieldat the time before treatment to $79.46 \pm 7.98 \% /$ visual fieldat 3 weeks after the last treatment, while the mean collagen density at the treatment group decreased from $87.69 \pm 7.00 \% /$ visual fieldat the time before therapy to $79.31 \pm 7.58 \% /$ visual field at 3 weeks after the last treatment.

The decrease difference of collagen density between the control group and the treatment group was not significant (Table 1). The mean degradation of collagen density from pretreatment to post-treatment in the control group was $-5.69 \pm 6.41 \%$ /visual field, whereas the mean decrease ofcollagen density from pretreatment to post-treatment in the treatment group was $8.38 \pm 7.31 \% /$ visual field. The mean difference of collagen density degradation between the two groups was -2.69 with $\mathrm{p}=0.328$.

\section{Discussion}

This study is an open controlled clinical trial that aimed to compare the effectivity of $\mathrm{CO}_{2}$ fractional laser and triamcinolone acetonide injections combination therapy with standard therapy of triamcinolone acetonide monotherapy. After 6 months sampling, 26 study participants fulfilled the inclusion criteria. Study participants who have been injected with triamcinolone acetonide should be longer than 4 weeks before the study begins. All of the enrolled study participants have not received a fractional $\mathrm{CO}_{2}$ laser therapy. The studied keloid does not include the face, ears, and neck area. All study participants had good general conditions and did not have systemic disease.

The age of study participants was determined in the range of 15-64 years. No younger than 15 years old because of concern the patient can not cooperate during the research procedure. The age of 15 and above is also selected according to the WHO adult criteria. ${ }^{11}$ Not older than 64

Table 1. Timeline of treatment schedule in research.

\begin{tabular}{|c|c|c|}
\hline Initial visitation & Visitation II & Visitation III \\
\hline Week 0 & $3^{\text {rd Week }}$ & $6^{\text {th }}$ Week \\
\hline $\begin{array}{l}\text { Skin biopsy and lesion measurement } \\
\text { of pre treatment, followed by } \\
\mathrm{CO}_{2} \text { laser (treatment group only), } \\
\text { then injection of the } 1^{\text {st }} \text { triamcinolone }\end{array}$ & $\begin{array}{l}2^{\text {nd }} \text { triamcinolone } \\
\text { Injection }\end{array}$ & $\begin{array}{l}\text { Skin biopsy and post } \\
\text { treatment measurement } \\
\text { of the lesion }\end{array}$ \\
\hline
\end{tabular}

Table 2. Result of analysis of difference of degradation of collagen density between control and treatment group using T-Test.

\begin{tabular}{lcccc} 
Decrease density of collagen & Mean (SD) & Difference & CI 95\% & p value \\
Control group & $-5.69(6.41)$ & -2.69 & $(-2,87)-(8,26)$ & 0.328 \\
\hline
\end{tabular}


years-old because the invasive procedure of this study is feared to affect the general condition of the patient. The mean age of the subjects in this study was 29.4 years-old. Most participants were in the 15-24 year age group $(53.8 \%)$, followed by the $25-34$ year age group. Participants of female sex (57.7\%) slightly more than men.

According to Chike-Obi et al. keloid can occur at all ages, the incidence is highest at the age of 11-30 years, and slightly more in women. ${ }^{2}$ Age between the treatment group and the control group in this study did not differ significantly $(p=0.537)$, and also the sex of the study subjects between the two study groups ( $\mathrm{p}=0.694$ ).

The duration of illness was not homogeneous between the control group and the treatment group, as there were patient who suffer keloid for 15 years in the treatment group. The patient was not excluded from the study because it met the inclusion criteria. The length of illnessin study subjects varied from 6 months to 15 years. A total of 9 patients (34\%) had ever undergone standard treatment, intralesional triamcinolone acetonide injections. A total of 4 patients are still undergoing several injection sessions, so there is no change from the initial condition. These patients complain of pain during the injection so theyunderwent the treatment regularly. ${ }^{12}$

Patients who did not undergo standard treatment will not get the maximum treatment result. There were 3 patients who had undergone surgical removal of keloid, then the three patients had keloid relapse. This is in accordance with the literature which states that keloid recurrence after excision is $45-100 \%$ if not accompanied by adjuvant therapy. ${ }^{12}$

Histopathological parameters were rare in the study of keloids, most of which were prameters of scar assessment scores. ${ }^{13,14}$ This study attempts to prove that triamcinolone acetonide and combination therapy can decrease the collagen density. Triamcinolone significantly decreased the collagen density in the control and combination therapy group,but the difference of degradation was insignificant (Table 1). It could be caused by thelaser therapy in the combination therapywas performed only once and the evaluation time was only 6 weeks after treatment.

Triamcinolone acetonide in the both group suppresses fibroblast proliferation and enhance fibroblast degeneration, thus decrease collagen production. Triamcinolone acetonide also has vasoconstriction effect that diminish vascularization to keloid. ${ }^{15}$ The fractional $\mathrm{CO}_{2}$ lasers decrease the collagen density in a some ways. It enhance fibroblast proliferation, but diminish TGF- $\beta$ that has pivotal role in collagen synthesis. It also shorten collagen fiber to one-third of initial length. ${ }^{10}$ The MTZ depth that formed by fractional $\mathrm{CO}_{2}$ laser is about $400 \mu \mathrm{m}$. The depth has reached the depth of papillary dermis, so that MTZ can be a depot and assist in the distribution of injected triamcinolone acetonide. The collagen density decreasedmore significant after fractional $\mathrm{CO}_{2}$ laser-triamcinolone injection combination therapy in only 6 weeks follow up (1 laser and 2 times triamcinolone acetonide injection) than after triamcinolone injection alone. It suggest that the combination therapy gives a sinergis effect.

\section{Conclusions}

The collagen density that decrease significantly in a shorter time shows that fractional $\mathrm{CO}_{2}$ laser-triamcinolone acetonide injection could be a good combination therapy. Fractional $\mathrm{CO}_{2}$ laser gives a sinergis effect to intralesional triamciolone acetonide injection. The combination therapy is an effective keloid therapy and may become the alternative for intralesional triamcinolone acetonide monotherapy. Intralesional triamcinolone acetonide monotherapy remains the manstays for keloid therapy, because the combination therapystill not showed a significant deference to triamcinolone acetonide injection monotherapy.

\section{References}

1. Ko CJ. Dermal hypertrophies and benign fibroblastic/myofibroblastic tumours. In: Goldsmith LA, Katz SI, Gilchrest BA, Paller AS, Leffell DJ, Wolff K, editors. Fitz patrick's dermatology in general medicine. 8th ed. New York. Mc Graw Hill; 2012. p. 707-10.

2. Chike-Obi CJ, Cole PD, Brissett AE. Keloids: pathogenesis, clinical features, and management. Semin Plast Surg 2009; 23: 178-84.

3. Monstrey S, Middelkoop E, Vranckx JJ, et al. Updated scar management practical guidelines: non-invasive and invasive measures. JPRAS 2014; 67: 1017 25.

4. Butler PD, Longaker MT, Yang GP.
Current progress in keloid research and treatment. J Am Coll Surg 2008; 206: 731-41.

5. Moshref SS, Mufti ST. Keloid and hypertrophic scar: comparative histopathological and immunohistochemical study. JKAU Med Sci2010; 17: 3-22.

6. Khan MA, Bashir MM, Khan FA. Intralesional triamcinolone alone and in combination with 5-fluorouracil for the treatment of keloid and hypertrophic scars. JPMA 2014; 64: 1003-7.

7. Garg GA, Sao PP, Khopkar US. Effect of carbon dioxide laser ablation followed by intralesional steroids on keloids. J Cutan Aesthet Surg 2011; 4: 2-6.

8. Waibel JS, Wulkan AJ, Shumaker PR. Treatment of hypertrophic scars using laser and laser assisted corticosteroid delivery. Lasers Surg Med 2013; 45:135-40

9. Listiawan MY. Fractional Photothermolysis in Laser. In: Lumintang H, Listiawan MY, Prakoeswa CRS, Bandem AW, editors. Recent Management of Dermatology in Daily Practice. Surabaya: Insan Cendekia; 2013. p. 41-54.

10. Tanzi EL, Alster TS. Ablative lasers, chemical peels, and dermabrasion. In: Goldsmith LA, Katz SI, Gilchrest BA, et al. Fitz patrick's dermatology in general medicine. 8th ed. New York. Mc Graw Hill; 2012. p. 3021-31.

11. World Health Organization. International statistical classification of diseases and related health problems 10th revision. 4th ed. Geneva: WHO Press; 2011.

12. Robles DT, Berg D. Abnormal wound healing: keloids. Clin Dermatol 2007; 25: 26-32.

13. Sharquie KE, Noaimi AA, Al-Karhi MR. Debulking of keloid combined with intralesional injection of 5-fluorouracil and triamcinolone versus intralesional injection of 5-fluorouracil and triamcinolone. JCDSA 2014; 4: 85 91.

14. Draaijers LJ, Tempelman FR, Botman YA, et al. The patient and observer scar assessment scale: a reliable and feasible tool for scar evaluation.Plast Reconstr Surg 2004; 113: 1960-5.

15. Cruz NI, Korchin L. Inhibition of human keloid fibroblast growth by isotretinoin and triamcinolone acetonide in vitro. Ann Plast Surg 1994; 33 : 401-5. 